\title{
A Preliminary Investigation of PVT1 on the Effect and Mechanisms of Hepatocellular Carcinoma: Evidence from Clinical Data, a Meta-Analysis of 840 Cases, and In Vivo Validation
}

\author{
Yu Zhang ${ }^{a}$ Dong-yue Wen ${ }^{b}$ Rui Zhang ${ }^{a}$ Jia-cheng Huang ${ }^{a}$ Peng Lin ${ }^{b}$ \\ Fang-Hui Ren ${ }^{\mathrm{a}}$ Xiao Wang ${ }^{\mathrm{c}}$ Yun $\mathrm{He}^{\mathrm{b}}$ Hong Yang $^{\mathrm{b}}$ Gang Chen $^{\mathrm{a}}$ \\ Dian-Zhong Luo
}

\begin{abstract}
aDepartment of Pathology, First Affiliated Hospital of Guangxi Medical University, Nanning, bDepartment of Medical Ultrasonics, First Affiliated Hospital of Guangxi Medical University, Nanning, 'Department of Orthopedics, Shandong Provincial Hospital affiliated to Shandong University, Jinan, China
\end{abstract}

\section{Key Words}

Pvt1 • Hepatocellular carcinoma $・$ TCGA $・$ GEO $・$ CAM $・$ MiR-424-5p • INCENP

\begin{abstract}
Background/Aims: Hepatocellular carcinoma (HCC) remains a difficult problem that significantly affects the survival of the afflicted patients. Accumulating evidence has demonstrated the functions of long non-coding RNA (IncRNA) in HCC. In the present study, we aimed to explore the potential roles of PVT1 in the tumorigenesis and progression of HCC. Methods: In this study, quantitative reverse transcription-polymerase chain reaction (RTqPCR) was applied to detect the differences between PVT1 expression in HCC tissues and cell lines. Then, the Cancer Genome Atlas (TCGA) and Gene Expression Omnibus (GEO) databases were searched to confirm the relationship between PVT1 expression and HCC. Moreover, a meta-analysis comprising TCGA, GEO, and RT-qPCR was applied to estimate the expression of PVT1 in HCC. Then, cell proliferation was evaluated in vitro. A chicken chorioallantoic membrane (CAM) model of HCC was constructed to measure the effect on tumorigenicity in vivo. To further explore the sponge microRNA (miRNA) of PVT1 in HCC, we used TCGA, GEO, a gene microarray, and target prediction algorithms. TCGA and GEO and the gene microarray were used to select the differentially expressed miRNAs, and the different target prediction algorithms were applied to predict the target miRNAs of PVT1. Results: We found that PVT1 was markedly overexpressed in HCC tissue than in normal liver tissues based on both RTqPCR and data from TCGA, and the overexpression of PVT1 was closely related to the gender and race of the patient as well as to higher HCC tumor grades. Also, a meta-analysis of 840
\end{abstract}

Y. Zhang and D.-y. Wen contributely equally to this work.

Gang Chen

and Hong Yang 
cases from multiple sources (TCGA, GEO and the results of our in-house RT-qPCR) showed that PVT1 gained moderate value in discriminating HCC patients from normal controls, confirming the results of RT-qPCR. Additionally, the upregulation of PVT1 could promote $\mathrm{HCC}$ cell proliferation in vitro and vivo. Based on the competing endogenous RNA (ceRNA) theory, the PVT1/miR-424-5p/INCENP axis was finally selected for further research. The in silico prediction revealed that there were complementary sequences between PVTI and miR424-5 $p$ as well as between miR-424-5p and INCENP. Furthermore, a negative correlation trend was found between miR-424-5p and PVT1 based on RT-qPCR, whereas a positive correlation trend was found between PVT1 and INCENP based on data from TCGA. Also, INCENP small interfering RNA (siRNA) could significantly inhibit cell proliferation and viability. Conclusions: We hypothesized that PVT1 could affect the biological function of HCC cells via targeting $m i R$ 424-5p and regulating INCENP. Focusing on the new insight of the PVT1/miR-424-5p/INCENP axis, this study provides a novel perspective for HCC therapeutic strategies.

(C) 2018 The Author(s)

Published by S. Karger AG, Basel

\section{Introduction}

Hepatocellular carcinoma (HCC) represents one of the most widespread malignancies, with extremely high rates of cancer-related deaths [1]. The majority cases are clustered in Asia and Africa, and half of these incidences and deaths have occurred in China due to chronic hepatitis B infections [1]. Though the most curative treatment is surgery, including tumor resection and liver transplantation, the high rates of postoperative recurrence and mortality remain the main obstacle for the longer survival of patients with HCC [2-4]. Taking these into consideration, it is essential to elucidate the mechanism underlying HCC, which might provide novel insights into the diagnosis and treatment of HCC patients.

Long non-coding RNAs (lncRNAs) are non-protein coding transcripts with lengths longer than 200 nucleotides [5]. It has been indicated has lncRNAs could affect different cellular functions and participate in various physiological and pathological progress [6]. Accumulating evidence has shown that the ectopic expression of lncRNAs could influence the progression of HCC by modulating the self-renewal ability of liver cancer stem cells (CSCs) and other biological functions, including proliferation, apoptosis, invasion, and metastasis [7-10]. Moreover, other articles have also reported that the aberrant expression of lncRNAs might be involved in regulating the chemotherapy resistance of HCC patients $[11,12]$. The lncRNA PVT1 is located at chromosome $8 \mathrm{q} 24$, which is known to be a cancer-related region [13]. Moreover, PVT1 functions as an oncogene via interacting with MYC, encoding microRNA (miRNA), and participating in DNA rearrangement [14]. Several studies have identified PVT1 overexpression could accelerate the development of cancers and reduce the sensitivity of cancer patients to chemistry [15-20]. It has been previously shown that PVT1 was highly expressedin HCCcompared with non-tumortissues, andits overexpression predictsrecurrence by our group and other groups [21]. We had also surveyed the genetic regulatory network of PVT1 in HCC through a gene microarray and RNAsequecing data mining with bioinformatics method to investigate the potential mechanism of PVT1 in HCC, and found that $D L C 1$ and the Hippo signaling pathway could be closely related to the function of PVT1 in HCC [21]; however, the functions of PVT1 in HCC remain still elusive. In the present study, we sought to explore

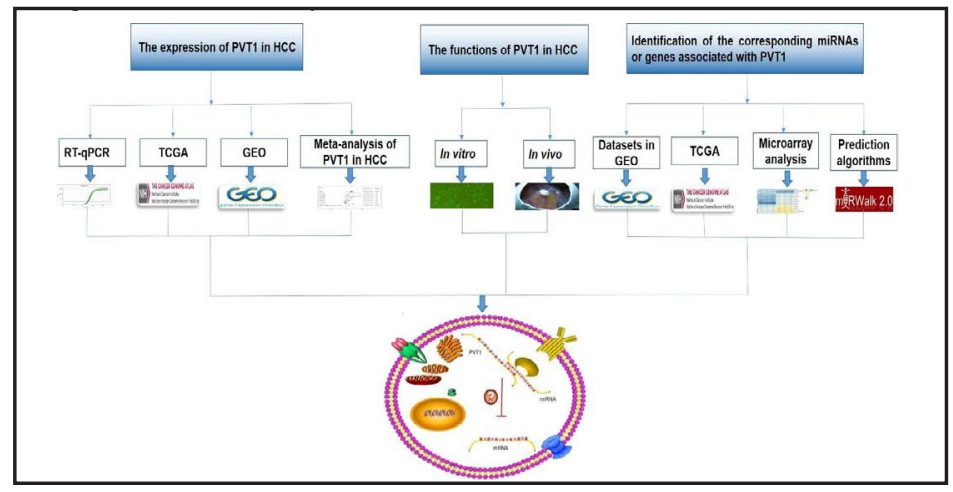

Fig. 1. A flow chart of this study. 


\section{Cellular Physiology Cell Physiol Biochem 2018;47:2216-2232 \begin{tabular}{l|l} 
DOI: 10.1159/000491534 & $\begin{array}{l}\text { O 2018 The Author(s). Published by S. Karger AG, Basel } \\
\text { www.karger.com/cpb }\end{array}$
\end{tabular} \\ Zhang et al.: PVT1 in Hepatocellular Carcinoma}

the clinical significance, effect, and molecular mechanism of PVT1 on the biological function of HCC cells at the cell, tissue, and animal levels. A flow chart of the current study is shown in Fig. 1.

\section{Materials and Methods}

\section{Patient Tissue Samples}

A total of 39 HCC cases from between August 2015 and January 2017 were collected from the Department of Pathology, First Affiliated Hospital of the Guangxi Medical University (Nanning, Guangxi, China). The age of these HCC patients ranged from 34 to 80 years. All patients were chosen randomly from a pool of cases who had received surgical resection without further treatment. All methods applied were according to the relevant regulations and guidelines, all experimental conventions were approved by the Ethical Committee of the First Affiliated Hospital of Guangxi Medical University, and consent forms for the use of the tissues in the study were signed by both the clinicians and patients. The pathological diagnoses were confirmed by two independent pathologists who did not know detailed patient information.

\section{Quantitative Real-Time PCR}

The total RNA was extracted via the Total RNA Kit (OMEGA, USA) based on the manufacturer's instructions. Then, the First Strand cDNA Synthesis Kit (Roche, USA) was applied to synthesize the total RNA into first-strand cDNA. The expression of PVT1 or miR-424-5p was normalized to GAPDH or miR-191 and miR-103 expression. Quantitative reverse transcription-polymerase chain reaction (RT-qPCR) was performed using the FastStart Universal SYBR Green Master (ROX) (Roche) in the Applied Biosystems 7500 Real-Time PCR System. The expression level of the genes was calculated by using Delta Delta Ct method [22, 23].

The primer sequences were as follows:

- PVT1-forward: AAGAGAAAGGAATCGGCACA

- PVT1-reverse: TGGTCGGATAGGGAGTCGT

- GAPDH-forward: CAGCACTCTGGACGGAC

- GAPDH-reverse: CAACAGGAGAAGCAAACA

- miR-424-5p: CAGCAGCAAUUCAUGUUUUGAA

- miR-191: CAACGGAAUCCCAAAAGCAGCU

- miR-103: AGCAGCAUUGUACAGGGCUAUGA

\section{PVT1 and HCC: A Meta-analysis}

The HCC-related PVT1 microarrays from GEO (http://www.ncbi.nlm.nih.gov/geo/) and ArrayExpress (http://www.ebi.ac.uk/arrayexpress/) were downloaded. The criteria used to determine study eligibility were as follows: 1) the study must be published in English and be a full essay; 2) it must include patients with HCC; 3) it must investigate the correlation of PVT1 expression with HCC; 4) it must use a prospective or retrospective cohort design with a clearly defined source population and justify all excluded eligible cases; 5) false positives, false negatives, true positives, and true negatives were provided or could be calculated from the data; and 6) when the same or similar samples of patients were investigated in several publications, the latest and most complete study was selected to avoid duplication. Also, the RNA-Seq datasets in TCGA (https://cancergenome.nih.gov/) database were used, which was updated up to 30th September, 2017. Furthermore, we conducted an RT-qPCR that we included in the meta-analysis. In addition, publications related to PVT1 in HCC were chosen from 12 online databases: PubMed, Embase, Google Scholar, Web of Science, Ovid, LILACS, Wiley Online Library, Science Direct, Chong Qing VIP, Cochrane Central Register of Controlled Trials, Wan Fang, Chinese CNKI, and China Biology Medicine disc. The retrieval was performed using the following keywords: PVT1 AND (hepatocellular OR liver OR hepatic OR HCC) AND (malignan* OR cancer OR tumor OR tumour OR neoplas* OR carcinoma). The literature retrieval was evaluated and crosschecked by two authors (Jia-cheng Huang and Peng Lin). If there was a disagreement, the group convened and discussed. 


\section{Cellular Physiology Cell Physiol Biochem 2018;47:2216-2232 \begin{tabular}{l|l} 
and Biochemistry Published online: July 05, 2018 & $\begin{array}{l}\text { (c) } 2018 \text { The Author(s). Published by S. Karger AG, Basel } \\
\text { www.karger.com/cpb }\end{array}$ \\
\hline
\end{tabular} \\ Zhang et al.: PVT1 in Hepatocellular Carcinoma}

\section{Cell Culture and siRNA Transfection}

The human HCC cell lines Bel-7402 and QGY-7703 and the normal liver cell line L02 were provided by the pathology laboratory (First Affiliated Hospital of Guangxi Medical University, China), and they were cultivated in Dulbecco's Modified Eagle's Medium (DMEM) complemented with 10\% fetal bovine serum (FBS) and 1\% penicillin-streptomycin. The SMMC-7721 and Bel-7404 HCC cell lines were purchased from the American Type Culture Collection (ATCC) and cultured in Roswell Park Memorial Institute (RPMI) 1640 medium supplemented with $10 \% \mathrm{FBS}$ and $1 \%$ penicillin-streptomycin. All cells were cultured at $37^{\circ} \mathrm{C}$ with $5 \% \mathrm{CO}_{2}$ in a humidified incubator.

The lentiviral small interfering RNA (siRNA) vector of PVT1 was synthesized by GeneChem (Shanghai, China; sense: 5'-CCCAACAGGAGGACAGCUUTT-3', antisense: 5'-AAGCUGUCCUCCUGUUGGGTT-3'). Both siRNA vectors that would silence the PVT1 gene and siRNA vectors that would not silence the gene were transfected into the SMMC-77221 cell line following the manufacturer's protocol.

In addition, four groups were designed to investigate the vital role of the target gene (INCENP) in HCC in the current study: mock control, scrambled siRNA, INCENP siRNA 1, and INCENP siRNA 2. Only the transfection reagent was added in the mock control group, whereas rearranged INCENP siRNA sequences were added to the scrambled siRNA group. Magnetofection (OZ Biosciences, Marseille, France) was performed for the transfection. The siRNA sequences were as follows: INCENP siRNA 1, 5'-GGACUUGGUGUGGCUUGAG-3'; INCENP SiRNA 2, 5'-TGACACGGAGATTGCCAAC-3'.

\section{Microarray Analysis}

To further survey the functions of PVT1 in HCC cells, Agilent's Human Gene Expression 4x44K Microarrays (v2) were applied to the PVT1-decreased SMMC-7721 cells and control cells. The Agilent Feature Extraction software (version 11.0.1.1) was utilized to obtain the original data, and the GeneSpring GX v12.1 software package (Agilent Technologies) was used to normalize and analyze the original data. We considered the genes to be significantly different when the fold change was $\geq 2$ and $P$ value was $\leq$ 0.05. In addition, we also conducted gene ontology (GO) and Kyoto Encyclopedia of Genes and Genomes (KEGG) pathway enrichment analyses using the GeneSpring GX v12.1 software package, which enabled us to understand the biological pathways related to the differentially expressed genes.

\section{Identification of the Corresponding miRNAs or Genes Associated with PVT1}

To further explore the corresponding miRNAs and genes associated with PVT1, the GEO and TCGA databases were used to further investigate the differentially expressed miRNAs or genes [24-26]. The differentially expressed miRNAs in the GEO database were chosen using the described vote-counting strategy [27]. In addition, four IncRNA/miRNA prediction algorithms were applied to predict the potential target miRNAs of PVT1. The four corresponding prediction algorithms were Tarbase (http://diana.imis. athena-innovation.gr/), starBase (http://starbase.sysu.edu.cn/), lncACTdb (http://210.46.85.180:8080/ LncACTdb/), and TANRIC (http://ibl.mdanderson.org/tanric/_design/basic/index.html). In addition, 12 target prediction algorithms were used to predict the potential target genes of the miRNAs. The 12 corresponding prediction algorithms were DIANA microT v4 (http://diana.imis.athena-innovation.gr/), miRDB (http://www.mirdb.org/), miRWalk (http://zmf.umm.uni-heidelberg.de/apps/zmf/mirwalk2/), miRmap (http://mirmap.ezlab.org/), miRanda (http://www.microrna.org), miRBridge (http://mirsystem. cgm.ntu.edu.tw/), PicTar2 (https://www.mdc-berlin.de/), miRNAMap (http://mirnamap.mbc.nctu.edu. tw/), RNA22 (https://cm.jefferson.edu/), PITA (https://genie.weizmann.ac.il/), TargetScan (http://www. targetscan.org/), and RNAhybrid (https://bibiserv.cebitec.uni-bielefeld.de/).

In this study, the downregulated miRNAs in the GEO and TCGA databases and the miRNAs selected by the target prediction algorithms were used to identify PVT1's corresponding miRNAs. Also, the upregulated genes in the GEO and TCGA databases, the downregulated genes identified from the microarray analysis after silencing PVT1 expression, and the genes selected by the target prediction algorithms were used to select the corresponding genes. In this process, Venn diagrams (http://bioinformatics.psb.ugent.be/ webtools/Venn/) were used to identify overlapping miRNAs or genes associated with PVT1 [28, 29].

Validation of the Expression of PVT1/miRNA/mRNA

In this study, RNA-Seq data, calculated on the Illumina HiSeq RNA-Seq platform, was obtained from TCGA, including 374 HCC tissues and 50 non-tumor tissues. The expression data were exhibited as reads 


\section{Cellular Physiology Cell Physiol Biochem 2018;47:2216-2232 \begin{tabular}{l|l} 
DOI: 10.1159/000491534 2018 & $\begin{array}{l}\text { O 2018 The Author(s). Published by S. Karger AG, Basel } \\
\text { www.karger.com/cpb }\end{array}$ \\
\hline
\end{tabular} \\ Zhang et al.: PVT1 in Hepatocellular Carcinoma}

per million, and the expression level was normalized via the DESeq R programming package. First, we identified the expression of PVT1 and its relationship with the clinical pathological parameters in HCC. Then we further identified the differences in miRNA and gene expressions between HCC tissues and normal liver tissues based on TCGA. In addition, the Spearman test was performed to investigate the correlation between PVT1 and miRNAs or genes. In addition, a receiver operating characteristic (ROC) curve was plotted to evaluate the clinical value of PVT1 expression. Furthermore, different datasets in the GEO database were used to confirm PVT1 expression in HCC. Finally, the Human Protein Atlas (HPA, http://www.proteinatlas. org/) database was used to clarify the immunohistochemical results of genes.

\section{Cell Proliferation}

In our current study, cell proliferation was evaluated through an MTT assay. Briefly, SMMC-7721 cells were washed twice with PBS when the cell density reached $80 \%$. The cell suspension was fabricated after being digested by trypsin, and then, cells were seeded into 96-well plates with $200 \mu \mathrm{L}$ of volume per well, each of which containing $3 \times 10^{3}-6 \times 10^{3}$ cells. Subsequently, MTT (20 $\mu \mathrm{L}, 5 \mathrm{mg} / \mathrm{mL}$; Sigma, USA) was seeded into each well, and the cells were then incubated at $37^{\circ} \mathrm{C}$ with $5 \% \mathrm{CO}_{2}$ for $4 \mathrm{~h}$. Dimethyl sulfoxide (DMSO; $150 \mu \mathrm{L}$ ) was placed into each well, and the cells were softly shaken for nearly $10 \mathrm{~min}$ to dissolve the crystal. A microplate reader was applied to distinguish the absorbance value at $490 \mathrm{~nm}$ at $12 \mathrm{~h}, 24 \mathrm{~h}, 48 \mathrm{~h}, 72 \mathrm{~h}$, and $96 \mathrm{~h}$.

Cell viability was evaluated through the fluorimetric detection of resorufin (CellTiter-Blue Cell Viability Assay, Promega, Madison, WI, USA) further confirm the results of the MTT assay. The procedure was performed based on the manufacturer's instructions. An FL600 fluorescence plate reader (Bio-Tek, Winooski, VT, USA) was applied for fluorimetry (excitation $=560 \mathrm{~nm}$, emission $=590 \mathrm{~nm}$ ). Fluorescence data were calculated as the fluorescence of treated sample/mock control $\times 100 \%$.

\section{Chorioallantoic Membrane Model of HCC}

Fertilized chicken eggs were purchased from a local hennery where they had been stored at $10^{\circ} \mathrm{C}$ and were then incubated at $37^{\circ} \mathrm{C}$. Then, SMMC-7721 cells from three groups (blank group, negative control, and the PVT1 siRNA group) were seeded into the chicken embryo chorioallantoic membrane (CAM; $2.5 \times$ 106 cells per egg) after eight days of incubation in an incubator. Five chicken eggs were included in each group. Subsequently, the tumor growth and embryo viability were observed daily through the SZ61 Zoom Stereo Microscope (Olympus, Japan). The tumor xenografts were carefully removed from the CAMs, fixed with paraformaldehyde and embedded in paraffin after five days [30]. The size of the tumor xenografts was recorded, and the xenografts' sizes were recorded as 0 if the length of the xenograft was less than $0.2 \mathrm{~cm}$.

\section{The Potential Pathways Associated with PVT1 and miRNAs}

To further investigate the fundamental functions and pathways associated with PVT1 and miRNAs in HCC, bioinformatics analyses, including GO and KEGG analyses, were performed as described [31, 32]. Genes with more than three overlapping nucleotide sequences (either those genes listed as overexpressed in the GEO database and TCGA, shown to be downregulated in the gene microarray, or identified as the target genes of miR-424-5p by more than five prediction algorithms) were used for bioinformatics analysis. The Database for Annotation, Visualization and Integrated Discovery (DAVID; http://david.abcc.ncifcrf. gov/) was used for GO and KEGG analyses. Three independent categories (biological process [BP], cellular component [CC], and molecular function [MF]) were derived separately from the GO analysis. Also, a GO functional network was constructed via Cytoscape (v2.8, http://cytoscape.org).

\section{Statistical Analysis}

A statistical analysis was carried out using SPSS v22.0. A Student's $t$-test was conducted to discover the difference between two groups, and Kruskal-Wallis $H$ test was used to estimate the relationship between three or more groups. The summary statistics between the different groups were exhibited as mean \pm standard deviation (mean \pm SD). A ROC curve was drawn to distinguish HCC from normal liver tissues by gene expression. Statistical significance was considered to be a $P$ value was lower than 0.05 (two sides). In addition, all experiments were repeated six times.

\section{KARGER}




\begin{tabular}{|c|c|c|}
\hline \multirow{2}{*}{$\begin{array}{l}\text { Cellular Physiology } \\
\text { and Biochemistry }\end{array}$} & \multicolumn{2}{|c|}{ Cell Physiol Biochem 2018:47:2216-2232 } \\
\hline & 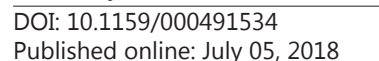 & $\begin{array}{l}\text { O } 2018 \text { The Author(s). Published by S. Karger AG, Basel } \\
\text { www.karger.com/cpb }\end{array}$ \\
\hline
\end{tabular}

\section{Results}

PVT1's Upregulation in HCC Tissues and Cells and Its Association with Clinical Pathological Factors

To investigate the differential expression of PVT1 in HCC and non-cancerous liver tissue, an RT-qPCR was performed. The results showed that PVT1 was remarkably upregulated in HCC tissues compared with the corresponding normal tissues $(P<0.001 ;$ Fig. $2 \mathrm{~A})$. Also, we conducted a ROC curve analysis to confirm the value of PVT1 in HCC. The area under the curve (AUC) of PVT1 was 0.857 (95\% confidence interval [CI] 0.775 0.939; $P<0.001$; Fig. $2 \mathrm{~B}$ ), and the sensitivity and specificity were 0.775 and 0.939 , respectively. Furthermore, in comparison with the L02 cell line, PVT1 was overexpressed in HCC tumor cell lines, especially SMMC-7721 $(P=0.025)$ and Bel-7404 $(P=0.049$; Fig. $2 C)$. In addition, to further confirm the high expression of PVT1 in HCC tissues and its potential role in the progression of HCC, we searched TCGA for relevant tissue data, resulting in 374 HCC tissues and 50 non-tumor tissues. Compared with the corresponding normal tissues, PVT1 was overexpressed in HCC tissues $(P<0.001$; Fig. 2D). Moreover, the AUC of PVT1 was 0.822 (95\% CI $0.780 \sim 0.863$; $P<0.001$; Fig. 2E), and the sensitivity and specificity were 0.780 and 0.863 , respectively, confirming the results of the RT-qPCR. As shown in Table 1, the expression level of PVT1 was higher in male patients than in female patients, and it was also higher in Asian patients than in white or black patients $(P<0.05$; Fig. $2 \mathrm{~F}, 2 \mathrm{G})$. Compared with the corresponding control groups, $P V T 1$ was also increased in HCC patients with advanced pathological grades $(P=0.003$; Fig. $2 \mathrm{H})$. Additionally, we investigated the role of PVT1 expression in patients' survival. It was observed that patients with low PVT1 expression survived for longer (64.31 \pm 5.17 months) compared to patients with high $P V T 1$ expression (59.59 \pm 4.75 months; $P=$ 0.241; Fig. 2I). These results suggest that IncRNA PVT1 might serve as an oncogene for HCC.

In addition, seven datasets in the GEO database (GSE54236, GSE49515, GSE60502, GSE58208, GSE98269, GSE57957, and GSE49713) were selected, and their expression data was used to evaluate PVT1 expression. As results, we found that PVT1 was upregulated in datasets of GSE49515, GSE58208, GSE98269, GSE57957, and GSE49713, whereas PVT1 was downregulated in datasets of GSE54236 and GSE60502 (Table 2). The Mean \pm SD of each

Fig. 2. Clinical significance of IncRNA PVT1 in HCC based on RTqPCR and the Cancer Genome Atlas (TCGA) database. (A) Differential expression of PVT1 in HCC and non-cancerous liver tissue based on RT-qPCR; (B) ROC curve of PVT1 in HCC based on RT-qPCR; (C) Differential expression of PVT1 between HCC cell lines and normal liver cell line LO2 (*** $\mathrm{P}<0.001)$; (D) Differential expression of PVT1 between HCC and non-cancerous liver tissue based on TCGA; (E) ROC curve of PVT1 in HCC based on TCGA; (F) male vs. female; (G) White vs Yellow vs Black; (H) G1G2 vs G3-G4; (I) Kaplan-Meier curves of PVT1 expression in HCC.

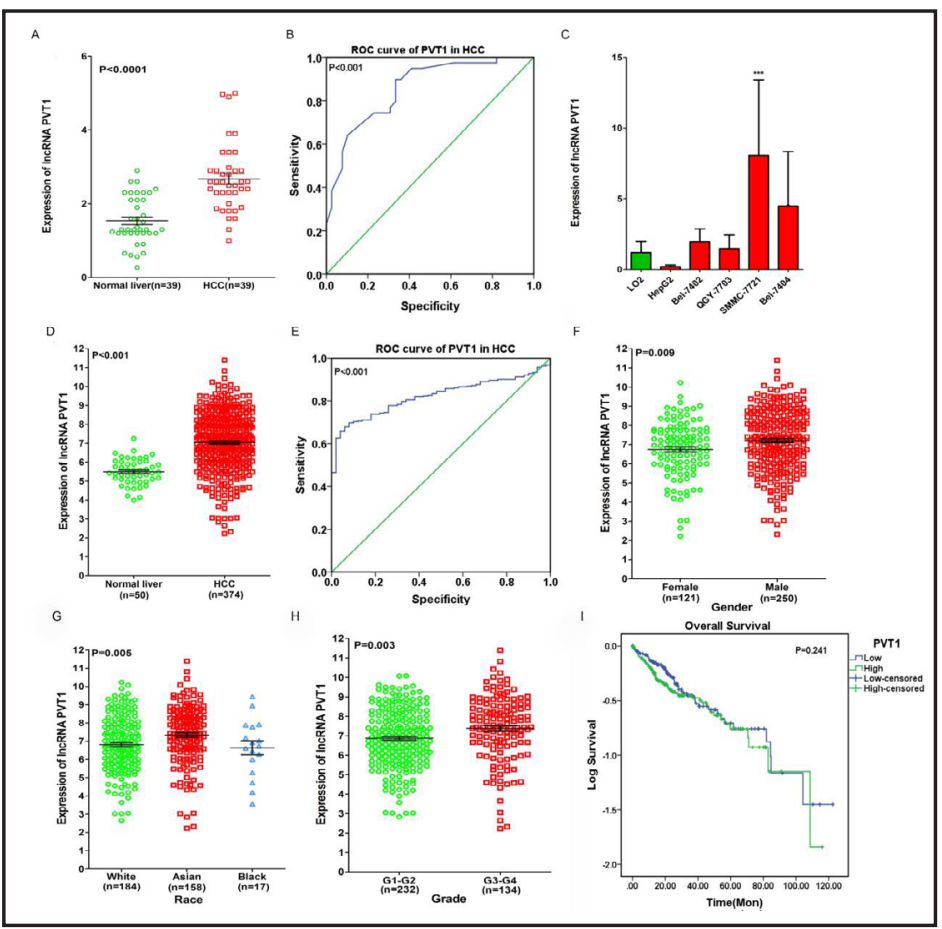


dataset was shown in Table 2.

PVT1 and HCC: $A$ Meta-
analysis of 840 Cases

After retrieving the datasets from the GEO database, 25 datasets were researched based on the keywords, and 18 datasets were excluded for not meeting our criteria. As a result, the meta-analysis included 840 cases from multiple centers (seven datasets from the GEO database [GSE54236, GSE49515, GSE60502, GSE58208, GSE98269, GSE57957 and GSE49713], the in-house RT-qPCR, and the original data in TCGA). The characteristics of these datasets included in the study are shown in Table 2 . As a result, the coalescent sensitivity and specificity of PVT1 were 0.59 (0.41-0.76) and 0.89 (0.71-0.96; Fig. $3 \mathrm{~A})$, respectively. The DLR negative and DLR positive were $0.46 \quad$ (0.31-0.69) and 5.27 (2.05-13.52, Fig. 3B), respectively. The diagnostic score and odds ratio was 2.44 (1.38-3.51) and 11.49 (3.96-33.35; Fig. 3C), respectively. The AUC of the summary ROC (SROC) was 0.81 (0.77-0.84; Fig. 4A), which indicates that PVT1 could be of moderate value in discriminating HCC patients from normal controls. As for the publication bias, no significant publication bias was found $(P=0.77$; Fig. 4B).

As for the PVT1 expression in the HCC group compared with the normal group, a fixed-effects model was chosen to evaluate the
Table 1. Differential expression of PVT1 by clinicopathological parameter in HCC based on TCGA

\begin{tabular}{|c|c|c|c|c|c|}
\hline \multirow{2}{*}{\multicolumn{2}{|c|}{ Clinicopathological parameter }} & \multirow[b]{2}{*}{$\mathrm{N}$} & \multicolumn{3}{|c|}{ PVT1 expression } \\
\hline & & & Mean \pm SD & $\mathrm{T}$ (or $\mathrm{F}$ value) & $P$ value \\
\hline \multirow{2}{*}{ Tissues } & Normal liver & 50 & $5.489422 \pm 0.668832$ & 12.513975 & $1.3668 \mathrm{E}-24$ \\
\hline & HCC & 371 & $7.056765 \pm 1.581333$ & & \\
\hline \multirow[t]{2}{*}{ Age } & $<60$ & 169 & $7.077774 \pm 1.492637$ & 0.304945 & 0.760580 \\
\hline & $\geq 60$ & 201 & $7.027466 \pm 1.651080$ & & \\
\hline \multirow{2}{*}{ Gender } & Male & 250 & $7.205854 \pm 1.624156$ & 2.631100 & 0.008868 \\
\hline & Female & 121 & $6.748728 \pm 1.447285$ & & \\
\hline \multirow[t]{3}{*}{ Race } & White & 184 & $6.811340 \pm 1.524794$ & $F=5.436137$ & 0.004726 \\
\hline & Asian & 158 & $7.340178 \pm 1.603716$ & & \\
\hline & Black & 17 & $6.642498 \pm 1.575141$ & & \\
\hline \multirow{2}{*}{$\mathrm{T}$ (Tumor) } & T1-T2 & 275 & $7.045154 \pm 1.515520$ & -0.308312 & 0.758021 \\
\hline & T3-T4 & 93 & $7.103810 \pm 1.779489$ & & \\
\hline \multirow[t]{2}{*}{ Pathological Grade } & G1-G2 & 232 & $6.874460 \pm 1.490704$ & -2.970309 & 0.003172 \\
\hline & G3-G4 & 134 & $7.381550 \pm 1.707534$ & & \\
\hline \multirow[t]{2}{*}{ Stage } & I-II & 257 & $7.082526 \pm 1.534231$ & 0.105844 & 0.915768 \\
\hline & III-IV & 90 & $7.061877 \pm 1.750195$ & & \\
\hline
\end{tabular}

Table 2. Characteristics of datasets included in the study. Note: Mean1 \pm SD1 = HCC tissues, Mean0 \pm SD0 = non-tumor tissues. Ref NO. The sequential reference numbers of citations. Citations of microarray datasets are displayed in the end of References list, and there are no citations available for the following 3 datasets: GSE58208[54], GSE98269[55], GSE49713[56], thus website address was affiliated

\begin{tabular}{|c|c|c|c|c|c|c|c|c|}
\hline $\begin{array}{l}\text { First author } \\
\text { (publication } \\
\text { year) }\end{array}$ & $\begin{array}{l}\text { Ref } \\
\text { NO. }\end{array}$ & Country & $\begin{array}{l}\text { Data } \\
\text { source }\end{array}$ & $\begin{array}{c}\text { Test } \\
\text { method/platform }\end{array}$ & $\begin{array}{c}\text { Cancer } \\
\text { group }\end{array}$ & $\begin{array}{l}\text { Normal } \\
\text { controls }\end{array}$ & $\begin{array}{l}\text { Mean1 } \pm \\
\text { SD1 }\end{array}$ & $\begin{array}{l}\text { Mean0 } \pm \\
\text { SD0 }\end{array}$ \\
\hline Villa E et al. (2014) & [51] & Italy & $\begin{array}{c}\text { GEO: } \\
\text { GSE54236 }\end{array}$ & $\begin{array}{c}\text { Agilent } \\
\text { GPL6480 }\end{array}$ & 81 & 80 & $\begin{array}{c}7.988 \pm \\
0.743\end{array}$ & $\begin{array}{l}8.149 \pm \\
1.036\end{array}$ \\
\hline Shi M et al. (2013) & [52] & Singapore & $\begin{array}{l}\text { GEO: } \\
\text { GSE49515 }\end{array}$ & $\begin{array}{l}\text { Affymetrix } \\
\text { GPL570 }\end{array}$ & 10 & 10 & $\begin{array}{c}3.640 \pm \\
0.179\end{array}$ & $\begin{array}{c}3.602 \pm \\
0.049\end{array}$ \\
\hline $\begin{array}{l}\text { Wang YH et al. } \\
\text { (2014) }\end{array}$ & [53] & $\begin{array}{l}\text { Chinese } \\
\text { Taiwan }\end{array}$ & $\begin{array}{l}\text { GEO: } \\
\text { GSE60502 }\end{array}$ & $\begin{array}{l}\text { Affymetrix } \\
\text { GPL96 }\end{array}$ & 18 & 18 & $\begin{array}{c}6.512 \pm \\
0.745\end{array}$ & $\begin{array}{c}6.566 \pm \\
0.537\end{array}$ \\
\hline $\begin{array}{l}\text { Hui KM et al. } \\
\text { (2014) }\end{array}$ & [54] & Singapore & $\begin{array}{l}\text { GEO: } \\
\text { GSE58208 }\end{array}$ & $\begin{array}{l}\text { Affymetrix } \\
\text { GPL570 }\end{array}$ & 10 & 17 & $\begin{array}{c}3.963 \pm \\
0.122\end{array}$ & $\begin{array}{c}3.855 \pm \\
0.121\end{array}$ \\
\hline Xie Z et al (2017) & [55] & China & $\begin{array}{c}\text { GEO: } \\
\text { GSE98269 }\end{array}$ & $\begin{array}{c}\text { Agilent } \\
\text { GPL21047 }\end{array}$ & 3 & 3 & $\begin{array}{l}6.951 \pm \\
1.123\end{array}$ & $\begin{array}{l}5.844 \pm \\
0.087\end{array}$ \\
\hline $\begin{array}{l}\text { Wang K et al. } \\
\text { (2013) }\end{array}$ & [56] & China & $\begin{array}{c}\text { GEO: } \\
\text { GSE } 49713\end{array}$ & $\begin{array}{c}\text { Arraystar } \\
\text { GPL11269 }\end{array}$ & 5 & 5 & $\begin{array}{c}7.012 \pm \\
0.252\end{array}$ & $\begin{array}{c}6.196 \pm \\
0.660\end{array}$ \\
\hline $\begin{array}{l}\text { Mah WC et al. } \\
\text { (2014) }\end{array}$ & [57] & Singapore & $\begin{array}{l}\text { GEO: } \\
\text { GSE57957 }\end{array}$ & $\begin{array}{l}\text { Illumina } \\
\text { GPL10558 }\end{array}$ & 39 & 39 & $\begin{array}{c}7.627 \pm \\
0.203\end{array}$ & $\begin{array}{c}7.547 \pm \\
0.179\end{array}$ \\
\hline TCGA (2017) & $\mathrm{NR}$ & USA & TCGA & $\mathrm{NR}$ & 374 & 50 & $\begin{array}{c}7.044 \pm \\
1.582\end{array}$ & $\begin{array}{c}5.489 \pm \\
0.669\end{array}$ \\
\hline $\begin{array}{l}\text { RT-qPCR } \\
(2017)\end{array}$ & $\mathrm{NR}$ & China & RT-qPCR & NR & 39 & 39 & $\begin{array}{c}2.669 \pm \\
0.148\end{array}$ & $\begin{array}{c}1.536 \pm \\
0.104\end{array}$ \\
\hline
\end{tabular}

Fig. 3. Diagnostic metaanalysis of PVT1 in HCC. (A) The pooled sensitivity and specificity of the included studies, (B) the pooled positive DLR and negative DLR of the included studies, and (C) the pooled diagnostic score and diagnostic odds ratio of the included studies.

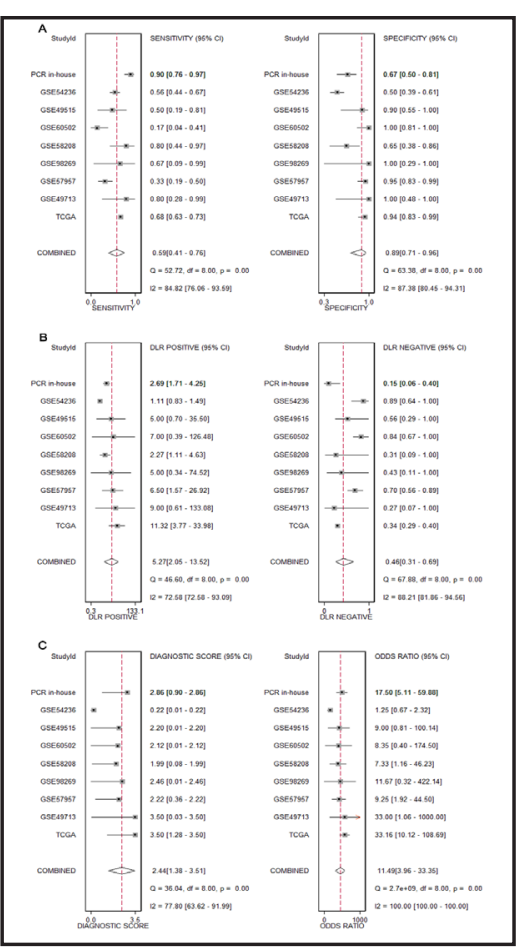


Fig. 4. Summary receiver operating characteristic (SROC) curve and publication bias of the included studies. (A) The SROC curve of PVT1 in HCC-the AUC of the SROC curve was $0.81(0.77-0.84)$ (B) publication bias, where $1 / \operatorname{root}(\mathrm{ESS})$ indicates the inverse root of the effective sample sizes and each circle represents an included study.

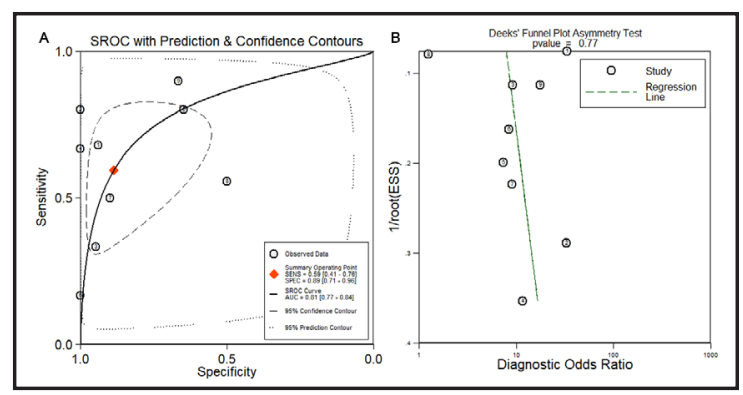

Fig. 5. Expression condition of PVT1 in HCC compared to normal liver. (A) Forest plot of datasets evaluating PVT1 expression between HCC and normal control groups (fixed-effects model); (B) forest plot of datasets evaluating PVT1 expression between HCC and normal control groups (randomeffects model); (C) funnel plot of datasets, and no publication bias was found in our investigation; (D) sensitivity analysis to determine which major studies should be excluded; and (E) forest plot of the remaining datasets evaluating PVT1 expression between HCC and normal control groups (fixedeffects model).

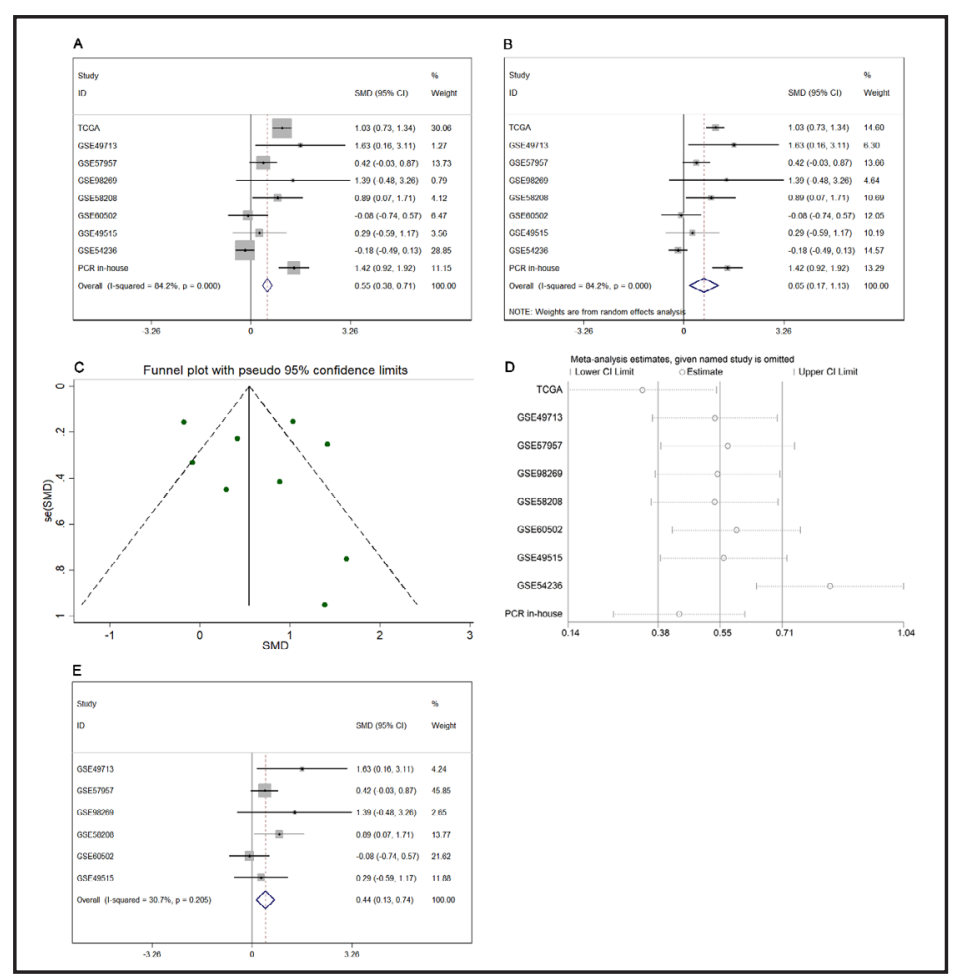

standard mean deviation (SMD), and the combined SMD was $0.55(0.38,0.71)$ with a high heterogeneity $\left(I^{2}=84.2 \% ; P<0.001 ;\right.$ Fig. $\left.5 \mathrm{~A}\right)$. Then, a random-effects model was applied, and the combined SMD was $0.65(0.17,1.13)$ with a heterogeneity greater than $50 \%$ (Fig. 5B). As for publication bias, no significant publication bias was found ( $P>0.05$; Fig. $5 \mathrm{C}$ ). In order to clarify whether a certain study contributed to the heterogeneity, a sensitivity analysis was applied to exclude two data sources (GSE54236 and the data in TCGA; Fig. 5D). Then, the fixed-effects model showed the combined SMD was $0.44(0.13,0.74)$, indicating that a higher expression of PVT1 could be found in the HCC group than in the normal groups (Fig. 5E).

In summary, the meta-analysis of PVT1 in HCC indicated that PVT1 was upregulated in HCC, and PVT1 has a moderate value in discriminating HCC patients from normal controls.

\section{A Comprehensive Analysis of the Gene Expression Profile with Knockdown of PVT1}

To explore the functions of PVT1 in the pathogenesis of HCC, we characterized a gene expression profile by silencing PVT1 expression. The light microscope and fluorescence microscope images after transfecting HCC cells with PVT1 RNAi are shown in Fig. 6A and Fig. 6B. The transfection efficiency was approximately 90\%, and the knockdown efficiency of PVT1 in HCC cells was over 75\% as detected by RT-qPCR (Fig. 6C). Also, the expression of $P V T 1$ in HCC cells was remarkably decreased in the Lv-siPVT1 group compared to the normal control group $(P=0.035)$ and the Lv-control group $(P=0.029$; Fig. $6 \mathrm{C})$. Based on a gene microarray analysis, 195 upregulated genes and 60 downregulated genes were significantly 
differentially expressed in the Lv-control and PVT1-RNAi groups. The top 50 differentially expressed genes are shown in Fig. 6D $(|\log 2 \mathrm{FC}|>1$, adjusted $P$ value $<0.05)$.

\section{Identification of the Corresponding miRNAs Associated with PVT1}

In this study, five miRNAs (miR-139-5p, miR-199a-3p, miR-199a-5p, miR-29c-3p, miR-424$5 p$ ) were selected as overlapping miRNAs among the downregulated miRNAs in TCGA and GEO database. After verification by four miRNA prediction algorithms (Tarbase, starbase, IncACTdb, and TANRIC), miR-424-5p was the only overlapping miRNA that corresponded with PVT1 (Fig. 7A). The complementary sequences between miR-424-5p and PVT1 are shown in Fig. 7B. To investigate the differential expression of miR-424-5p in HCC and noncancerous liver tissue, an RT-qPCR was performed. The results show that miR-424-5p was

Fig. 6. Transfection efficiency of PVT1 siRNA into HCC cells. (A) Light microscope, $\mathrm{x} 100$; (B) fluorescence, x100; (C) the expression of PVT1 in SMMC-7721 cells was remarkably decreased in the Lv-siPVT1 group compared to the normal control group and Lv-control group based on RTqPCR; (D) clustering heatmap visualization of genes differentially expressed among the experimental groups $(\mathrm{n}=3)$ and control groups ( $\mathrm{n}=3$ ) after PVT1 was knocked down in HCC cells. The values in the heatmap represent the levels of differentially expressed genes in each group.

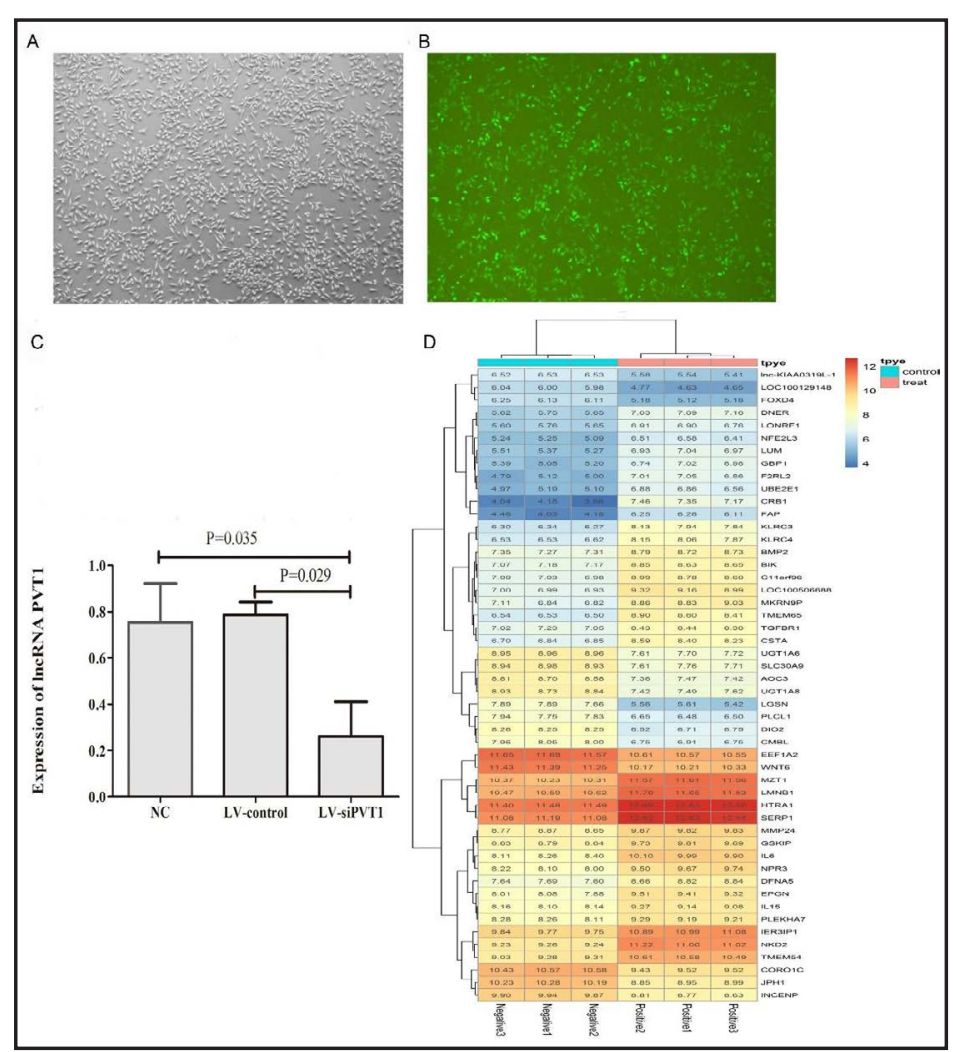

Fig. 7. Potential relationship between miR-424-5p and PVT1. (A) A flow chart to screen potential target miRNAs of PVT1; (B) Complementary sequences between miR-424-5p and PVT1; (C) The expression of miR-424-5p in HCC detected by RT-qPCR; (D) ROC curve of miR-424-5p in HCC based on RT-qPCR; (E) The relationship between the expression of miR424-5p and PVT1 based on RTqPCR; (F) Differential expression of miR-424 between HCC and non-

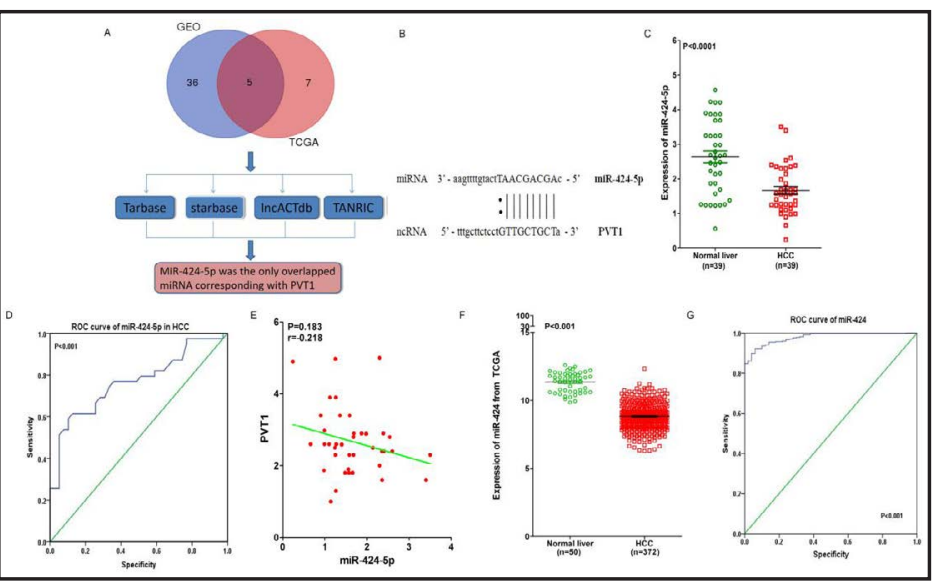
cancerous liver tissue based on TCGA; (G) ROC curve of miR-424 in HCC based on TCGA. 
clearly downregulated in HCC tissues compared with the corresponding non-tumor tissues $(P<0.001 ;$ Fig. 7C). Furthermore, a ROC curve analysis was conducted to measure the value of $m i R-424-5 p$ in HCC. The AUC of $m i R-424-5 p$ was 0.767 (95\% CI $0.660 \sim 0.874 ; P<0.001$; Fig. 7D). Moreover, a negative correlation trend was found between miR-424-5p and PVT1 $(r=-0.218 ; P=0.183$; Fig. 7E). In addition, based on TCGA, we found that miR-424 was clearly downregulated in HCC tissues compared to normal liver tissues $(P<0.001$; Fig. 7F). A ROC curve analysis was conducted to measure the value of miR-424 in HCC. The AUC of miR-424 was 0.978 (95\% CI 0.965 0.991; $P<0.001$; Fig. 7G). We also tried to further study the relationship between miR-424 and clinicopathological parameters based on TCGA, but no positive results were found (Table 3 ). Taken together, these results suggested that PVT1 might act as a miRNA sponge in HCC by targeting miR-424-5p.

\section{Identification of the Corresponding Genes Associated with PVT1}

To identify the key genes associated with PVT1 and miR-424-5p in HCC, only one gene expression profile (GSE57786) could be obtained from the GEO database, and the genes upregulated in GEO after PVT1 overexpression were screened out for subsequent evaluation. TCGA was searched to select the genes overexpressed in HCC. Additionally, the 60 downregulated genes after silencing PVT1 expression and the target genes of miR-424$5 p$ predicted by more than five prediction algorithms were also considered to be candidate corresponding genes. As a result, only one gene-INCENP-was selected out of all the genes above via Venn diagrams (Fig. 8A). Also, the complementary sequences between INCENP and $m i R-424-5 p$ are shown in Fig. 8B. Based on data from TCGA, we found that INCENP was clearly upregulated in HCC tissues compared to normal liver tissues $(P<0.001$, Fig. 8C). Also, a positive correlation trend was found between PVT1 and INCENP $(r=$ $0.039, P=0.421$, Fig. 8 D). Considering the relationship between INCENP and clinic op athological parameters, we found that high INCENP expression was positively related to tumor stage $(P=0.007$,

Table 3. Differential expression of miR-424 by clinicopathological parameter in HCC based on TCGA

\begin{tabular}{|c|c|c|c|c|c|}
\hline \multirow{2}{*}{\multicolumn{2}{|c|}{ Clinicopathological parameter }} & \multirow{2}{*}{$\mathrm{N}$} & \multicolumn{3}{|c|}{ miR-424 expression } \\
\hline & & & Mean \pm SD & $\mathrm{T}$ (or F value) & $P$ value \\
\hline \multirow{2}{*}{ Tissues } & Normal liver & 50 & $11.344194 \pm 0.740768$ & -17.799339 & $<0.001$ \\
\hline & $\mathrm{HCC}$ & 372 & $8.814054 \pm 0.967342$ & & \\
\hline \multirow{2}{*}{ Age } & $<60$ & 170 & $8.842633 \pm 1.015856$ & 0.496197 & 0.620051 \\
\hline & $\geq 60$ & 201 & $8.792519 \pm 0.928032$ & & \\
\hline \multirow{2}{*}{ Gender } & Male & 253 & $8.787174 \pm 0.924067$ & -0.781045 & 0.435275 \\
\hline & Female & 119 & $8.871202 \pm 1.055289$ & & \\
\hline \multirow[t]{3}{*}{ Race } & White & 182 & $8.894917 \pm 0.995177$ & $F=1.900547$ & 0.150996 \\
\hline & Asian & 161 & $8.695467 \pm 0.962687$ & & \\
\hline & Black & 17 & $8.914114 \pm 0.828981$ & & \\
\hline \multirow[t]{2}{*}{$\mathrm{T}$ (Tumor) } & T1-T2 & 276 & $8.798003 \pm 0.905297$ & -0.321656 & 0.748211 \\
\hline & T3-T4 & 93 & $8.839273 \pm 1.120200$ & & \\
\hline \multirow[t]{2}{*}{ Pathological Grade } & G1-G2 & 231 & $8.839320 \pm 1.013266$ & 0.736736 & 0.461755 \\
\hline & G3-G4 & 137 & $8.762365 \pm 0.888114$ & & \\
\hline \multirow[t]{2}{*}{ Stage } & I-II & 258 & $8.792441 \pm 0.909124$ & 0.351068 & 0.725751 \\
\hline & III-IV & 90 & $8.750941 \pm 1.112777$ & & \\
\hline
\end{tabular}

Fig. 8. Potential relationship between PVT1, miR424-5p, and INCENP. (A) A Venn diagram to screen the possible target genes of miR-424-5p (a: the genes overexpressed in GEO, b: the downregulated genes after the knockdown of PVT1, c: the genes overexpressed in TCGA, d: target genes of miR424-5p identified by prediction algorithms), (B) complementary sequences of miR-424-5p binding to INCENP 3'-UTR, (C) differential expression of INCENP in HCC and non-cancerous liver tissue, and (D) positive correlation between PVT1 and INCENP in TCGA.

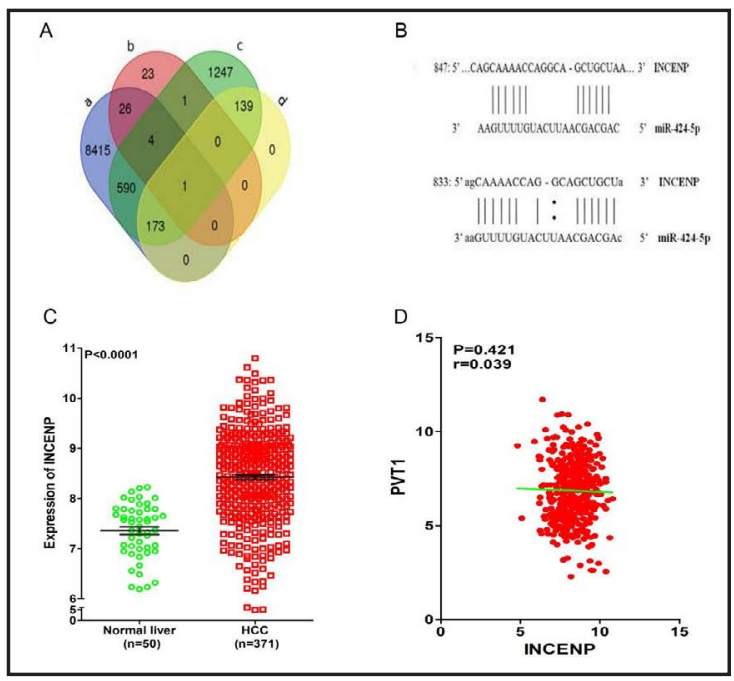


Fig. 9. Clinical significance of IncRNA INCENP in HCC based on TCGA database. (A) Differential expression of INCENP in group with TI-T2 vs. T3-T4, (B) G1-G2 vs. G3-G4, (C) stage I + II vs. stage III + IV , (D) ROC curve of INCENP in HCC, and (E) Kaplan-Meier curves of INCENP expression in HCC.

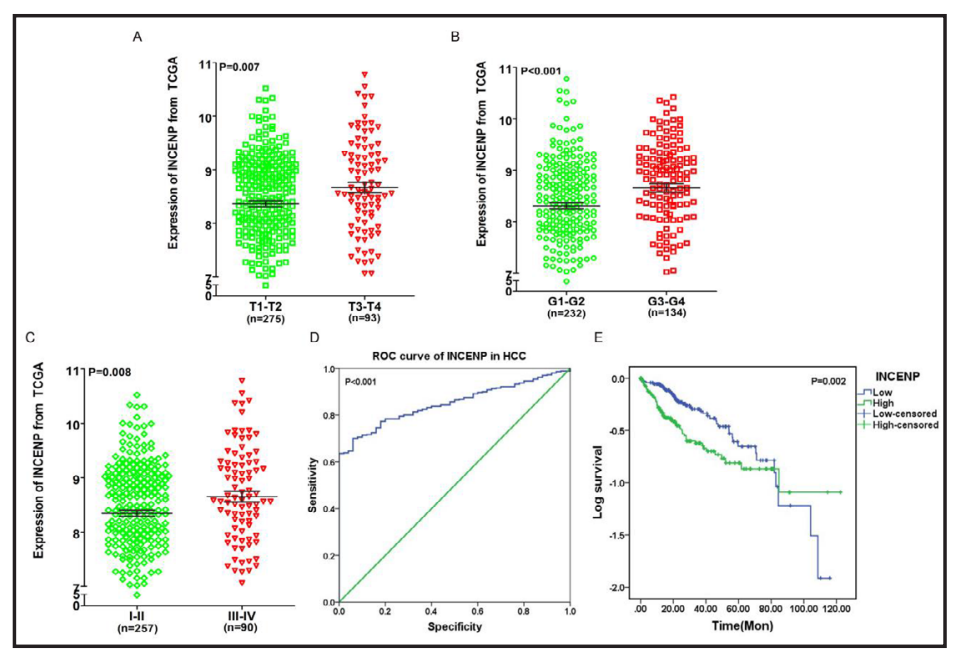

Fig. 9A), pathological grade $(P=0.001$, Fig. 9B $)$, and clinical stage $(P=0.008$, Fig. 9C, Table 4). In addition, a ROC curve was drawn to evaluate the value of INCENP for HCC. The AUC of INCENP was $0.850(95 \%$ CI 0.812 0.889; $P<0.001$; Fig. 9D). Additionally, we investigated the role of INCENP expression in patients' survival. It was observed that patients with Table 4. Differential expression of INCENP by other clinicopathological parameter in HCC based on TCGA

\begin{tabular}{|c|c|c|c|c|c|}
\hline \multirow{2}{*}{\multicolumn{2}{|c|}{ Clinicopathological parameter }} & \multirow{2}{*}{$\mathrm{N}$} & \multicolumn{3}{|c|}{ INCENP expression } \\
\hline & & & Mean \pm SD & $\mathrm{T}$ (or F value) & $P$ value \\
\hline \multirow{2}{*}{ Tissues } & Normal liver & 50 & $7.328732 \pm 0.542553$ & 12.175817 & $4.3552 \mathrm{E}-21$ \\
\hline & $\mathrm{HCC}$ & 371 & $8.436365 \pm 0.941299$ & & \\
\hline \multirow[t]{2}{*}{ Age } & $<60$ & 169 & $8.537884 \pm 1.000167$ & 1.935378 & 0.053710 \\
\hline & $\geq 60$ & 201 & $8.348287 \pm 0.883685$ & & \\
\hline \multirow{2}{*}{ Gender } & Male & 250 & $8.384874 \pm 0.991803$ & -1.619417 & 0.106477 \\
\hline & Female & 121 & $8.542751 \pm 0.820921$ & & \\
\hline \multirow[t]{3}{*}{ Race } & White & 184 & $8.403850 \pm 0.834785$ & $F=0.640381$ & 0.527698 \\
\hline & Asian & 158 & $8.533994 \pm 1.122029$ & & \\
\hline & Black & 17 & $8.514034 \pm 1.032755$ & & \\
\hline \multirow[t]{2}{*}{$\mathrm{T}$ (Tumor) } & T1-T2 & 275 & $8.363776 \pm 0.935627$ & -2.727720 & 0.006685 \\
\hline & $\mathrm{T} 3-\mathrm{T} 4$ & 93 & $8.669818 \pm 0.934447$ & & \\
\hline \multirow[t]{2}{*}{ Pathological Grade } & G1-G2 & 232 & $8.304814 \pm 0.919224$ & -3.474589 & 0.000573 \\
\hline & G3-G4 & 134 & $8.655748 \pm 0.950697$ & & \\
\hline \multirow[t]{2}{*}{ Stage } & I-II & 257 & $8.344186 \pm 0.944986$ & -2.667586 & 0.008000 \\
\hline & III-IV & 90 & $8.651506 \pm 0.927787$ & & \\
\hline
\end{tabular}

low INCENP expression survived for longer (66.11 \pm 4.55 months) compared to the high INCENP expression group (59.85 \pm 5.36 months, $P=0.002$, Fig. 9E).

To further evaluate the proliferation of HCC cells in the four different groups (i.e., mock control, scrambled siRNA, INCENP siRNA 1, and INCENP siRNA 2.), an MTT assay and viability assay were performed to evaluate the proliferation of HCC cells. In the results of the MTT assay, HCC cells exhibited a large cell proliferation inhibition, especially in the INCENP siRNA groups at $72 \mathrm{~h}(P$ $<0.01$, Fig. 10A). Consistent with the results of the MTT assay, the viability assay showed a clear inhibition of growth in the INCENP siRNA groups at $72 \mathrm{~h}(P<0.01$; Fig. 10B). Taken together, these results indicate that $P V T 1$ might contribute to the progression of HCC by modulating INCENP.

According to TCGA, we confirmed that INCENP expression was higher in HCC than that in normal liver tissues. Additionally, the immunohistochemical results of INCENP were

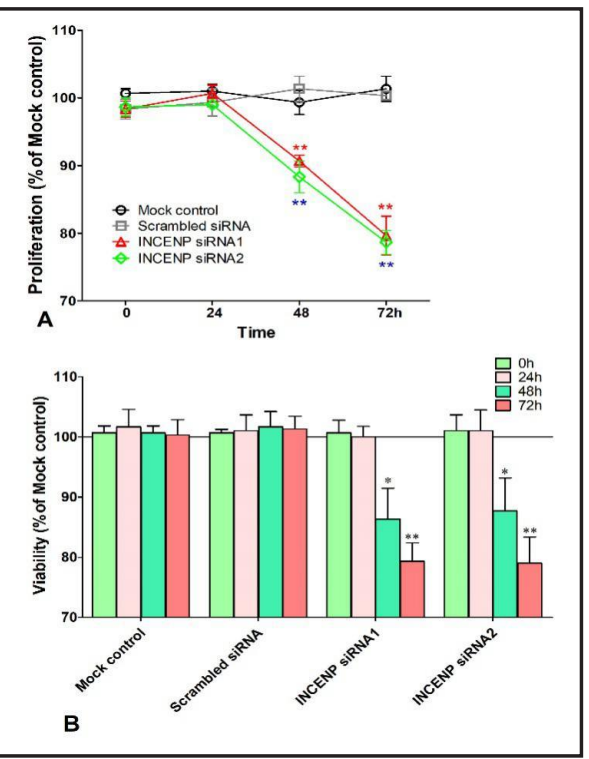

Fig. 10. Detection of the effect of INCENP on HCC cells proliferation. (A) Proliferation, (B) viability $\left({ }^{*} \mathrm{P}<0.05,{ }^{* *} \mathrm{P}<0.01\right)$ 
downloaded from the HPA database, which were applied to confirm INCENP expression. As shown in the HPA, INCENP could be detected in nucleus of cells. Also, INCENP was negatively stained in normal liver tissues, whereas INCENP was weakly positive stained in HCC tissues (Fig. 11). Considering the limiting samples in HPA database, no statistical analysis could be carried out. However, INCENP protein could be found in some HCC cells and none of the nonHCC cells, which was consistent with the over-expressed pattern of INCENP from TCGA data.

\section{The Upregulation of PVT1 Promotes HCC Cell Proliferation In vitro and Vivo}

To further verify the biological function of PVT1 in HCC, we detected the cell growth capacity in HCC cells after silencing the expression of PVT1. The results of an MTT assay showed that Lv-siPVT1 clearly inhibited SMCC-7721 cell proliferation at $96 \mathrm{~h}(P<0.05$; Fig. 12A). Furthermore, tumor formation experiments in a CAM model were conducted to evaluate the effect of PVT1 on tumorigenesis in vivo. The results showed that both the lvcontrol and PVT1-RNAi group could form tumors, and the tumorigenic ability of the PVT1RNAi group was significantly weakened $(P=0.08$, Fig. 12B).

Fig. 11. The immunohistochemical results of INCENP in HCC. INCENP was negatively stained in normal liver tissues (Patient id: 3222, A, B), INCENP was weakly positive stained in HCC tissues (Patient id: 2280, C. D). These immunohistochemical results were downloaded from HPA database with the antibody of "CAB013292".

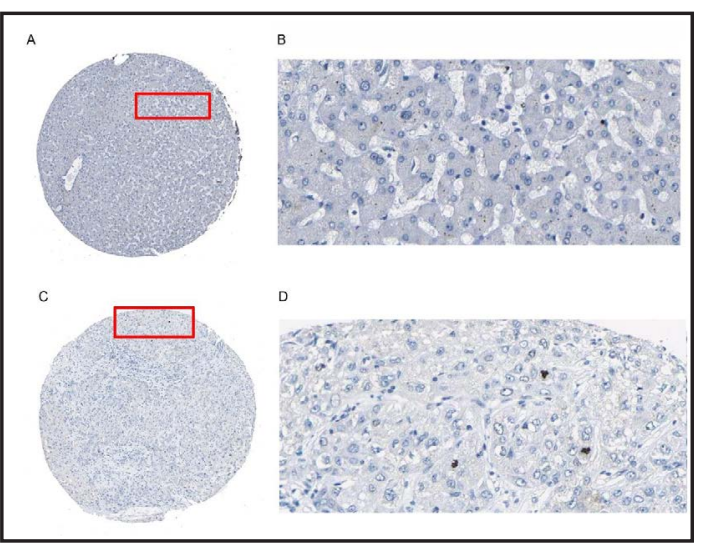

Fig. 12. Detection the effect of PVT1 on HCC growth. (A) Lv-siPVT1 inhibited the proliferation of HCC cells based on an MTT assay $\left({ }^{*} \mathrm{P}<0.05\right)$ and $(\mathrm{B})$ Comparison of the size of the HCC cell tumor xenografts after silencing PVT1 expression.

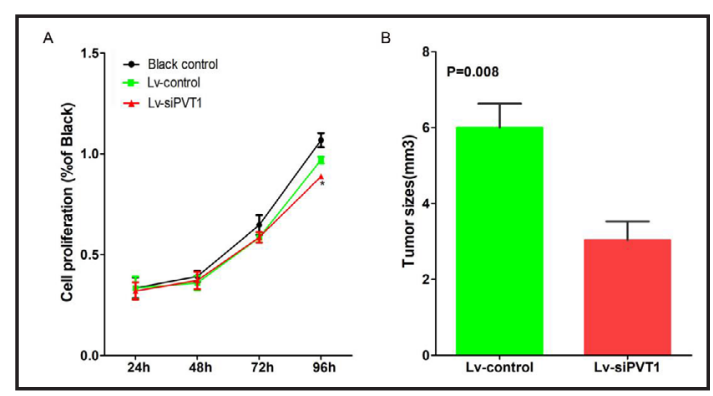

Table 5. Top 5 enrichment GO terms (BP, CC, and MF) of the 178 genes associated with PVT1 and miR-4245 p. Note: GO, gene ontology; BP, biological process; CC, cellular component; MF, molecular function

\begin{tabular}{|c|c|c|c|c|c|}
\hline GO ID & Term & $\begin{array}{c}\text { Categor } \\
y\end{array}$ & Count & $P$ value & Genes \\
\hline GO:0051301 & cell division & BP & 14 & $2.09 \mathrm{E}-05$ & $\begin{array}{l}\text { CCNF, KIF18B, BIRC5, CDC25A, CDC25B, CCNE2, CCNE1, KIF2C, NCAPH, OIP5, BUB1B, } \\
\text { SKA3, CCNO, CDCA4 }\end{array}$ \\
\hline GO:0007067 & mitotic nuclear division & $\mathrm{BP}$ & 11 & $9.84 \mathrm{E}-05$ & KIF2C, OIP5, INCENP, CCNF, SKA3, BUB1B, BIRC5, ANLN, CEP55, CDC25A, CDC25B \\
\hline GO:0007018 & microtubule-based movement & $\mathrm{BP}$ & 7 & $9.94 \mathrm{E}-05$ & KIF23, DYNC1I1, KIF2C, KIF24, KIF18B, RACGAP1, KIF21B \\
\hline GO:0000281 & mitotic cytokinesis & $\mathrm{BP}$ & 4 & 0.00232 & KIF23, ANLN, CEP55, RACGAP1 \\
\hline GO:0000082 & G1/S transition of mitotic cell cycle & $\mathrm{BP}$ & 6 & 0.002479 & CCNE2, CCNE1, IQGAP3, MCM2, CDC25A, CDT1 \\
\hline GO:0005871 & kinesin complex & CC & 5 & 0.001374 & KIF23, KIF2C, KIF24, KIF18B, KIF21B \\
\hline $\mathrm{GO}: 0005874$ & microtubule & CC & 10 & 0.002236 & KIF23, DYNC1I1, KIF2C, KIF24, INCENP, KIF18B, BIRC5, RACGAP1, KIF21B, EML6 \\
\hline GO:0000776 & kinetochore & CC & 5 & 0.006412 & DYNC1I1, KIF2C, INCENP, SKA3, BUB1B \\
\hline GO:0000777 & condensed chromosome kinetochore & CC & 5 & 0.008226 & DYNC1I1, KIF2C, INCENP, BUB1B, BIRC5 \\
\hline GO:0000785 & chromatin & $\mathrm{CC}$ & 5 & 0.008899 & OIP5, CHEK1, MCM2, HMGA1, TP73 \\
\hline GO:0003777 & microtubule motor activity & MF & 6 & $8.21 \mathrm{E}-04$ & KIF23, DYNC1I1, KIF2C, KIF24, KIF18B, KIF21B \\
\hline GO:0019901 & protein kinase binding & $\mathrm{MF}$ & 10 & 0.007677 & CCNE2, CCNE1, DBF4B, SQSTM1, EEF1A2, PFKFB2, RACGAP1, CDC25A, TP73, CDC25B \\
\hline GO:0004721 & phosphoprotein phosphatase activity & MF & 4 & 0.007983 & PGP, DUSP9, CDC25A, CDC25B \\
\hline GO:0003682 & chromatin binding & $\mathrm{MF}$ & 10 & 0.009774 & TICRR, TFAP2A, PYGO2, WHSC1, CBX2, PRKAA2, POLQ, LOXL2, HMGA1, TP73 \\
\hline GO:0005328 & $\begin{array}{l}\text { neurotransmitter: sodium symporter } \\
\text { activity }\end{array}$ & MF & 3 & 0.011495 & SLC6A8, SLC6A2, SLC6A15 \\
\hline
\end{tabular}




\section{Cellular Physiology \begin{tabular}{l|l|l} 
and Biochemistry 10.1159/000491534 & $\begin{array}{l}\text { C } 2018 \text { The Author(s). Published by S. Karger AG, Basel } \\
\text { www.karger.com/cpb }\end{array}$
\end{tabular}

Fig. 13. Gene Ontology (GO) enrichment analysis of 178 overlapping genes. Circular visualization of gene annotation enrichment analysis. The outer circle shows a scatter plot for the logFC of the enriched genes in each GO term ([A] biological process, [D] cellular component, and [G] molecular functions). Display of the relationship between a list of enriched genes and GO terms ([B] biological process, [E] cellular component, and $[\mathrm{H}]$ molecular functions). Hierarchical clustering of the enriched gene expression profiles in GO terms ([C] biological process, [F] cellular component, [I] molecular functions).

\section{The Potential Pathways}

Associated with PVT1

and miR-424-5p

In the current study, the GEO database, TCGA, a gene microarray, and prediction algorithms were all used to search for candidate genes, and 178 genes were selected for downstream analysis. Then, we explored the underlying gene functional pathways by GO and KEGG analyses based on these 178 genes. Consequently, cell division, protein kinase binding, as well as the kinesin complex were demonstrated to be strongly enriched biological terms that were closely associated with the progress of cancer (Table 5). To better comprehend the functions of these candidate genes, a function network was built based on the GO analysis (Fig. 13).

In addition, the KEGG pathway analysis showed that these genes were significantly overrepresented in the cell cycle and p53 signaling pathway, supporting our aforementioned result that PVT1 might play a vital role in the proliferation of HCC cells (Table 6). Altogether, the GO and KEGG pathway items reinforced the observation that PVT1 might be involved in HCC's biological mechanisms.

In summary, we hypothesized that PVT1 could affect the biological function of HCC cells by targeting miR-424-5p and regulating INCENP, and the implementation of these biological functions might be involved in the p53 signaling pathway. However, various functional experiments should be conducted to verify the precise mechanism.

\section{Discussion}

lncRNAs are involved in regulating gene expression and widen our understanding of its biological functions in diseases, including cancers [33, 34]. Emerging evidence has demonstrated the functions of IncRNAs in HCC, including lncRNA-PVT1 [7-10, 35]. As reported by xu et al., the overexpression of PVT1 in gastric cancer can predict the poor prognosis of gastric cancer patients and promote tumor cell proliferation and invasion via binding to FOXM1 [15]. Liu et al. also identified that PVT1 could serve as an oncogene in prostate cancer by activating the methylation of miR-146a and thereby promoting tumor growth [16]. Another study demonstrated that PVT1 expression was positively associated with tumor stage and metastasis, and increased expression of PVT1 could accelerate the progression of epithelial-mesenchymal transition (EMT) in esophageal cancer cells [36]. In addition, it has also been confirmed that the inhibition of PVT1 expression could enhance the sensitivity of cancer patients to drugs $[17,18,37]$. Despite this research, the role of PVT1 in HCC has remained elusive.

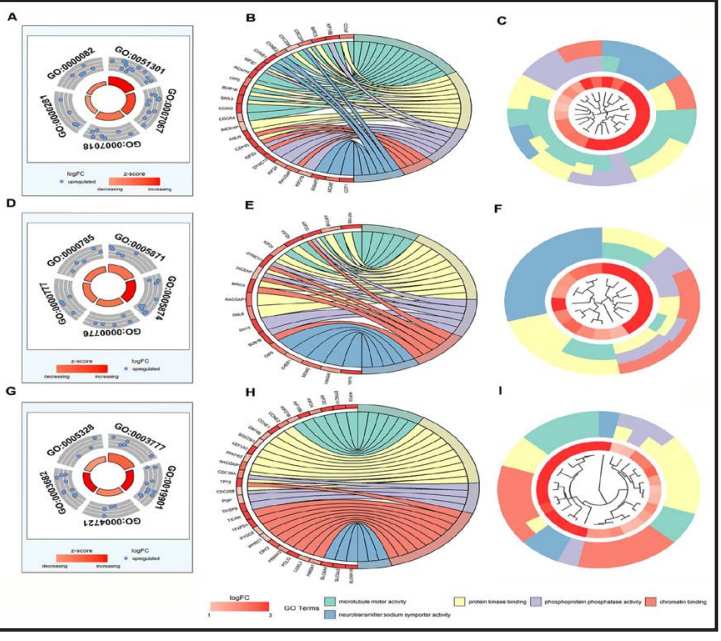

Table 6. KEGG pathway enrichment analysis of the 178 genes associated with PVT1 and miR-424-5p

\begin{tabular}{lccccc}
\hline KEGG ID & Term & $\begin{array}{c}\text { Categor } \\
\text { y }\end{array}$ & Count & P value & Genes \\
\hline hsa04110 & $\begin{array}{c}\text { Cell cycle } \\
\text { p53 signaling } \\
\text { pathway }\end{array}$ & KEGG & 7 & $4.18 \mathrm{E}-04$ & CCNE2, CCNE1, BUB1B, CHEK1, MCM2, \\
hsa04115 & 4 & 0.015965 & CDC25A, CDC25B \\
CCNE2, CCNE1, CHEK1, TP73
\end{tabular}


Our present study was the first to combine the analysis of data from GEO, TCGA, and gene microarrays to illustrate the biological functions of PVT1 in HCC. In this research, we found that PVT1 was increased in HCC tissues and cell lines, which was consistent with the results found by Ding et al. and Yu et al. $[35,38]$. In addition, this study was the first to use TCGA database to show that the upregulation of PVT1 in HCC tissues was highly associated with gender, race, and pathological grade. Ding et al.'s study demonstrated that the higher expression of PVT1 was strongly related with AFP level and predicted poor recurrencefree survival [38]. The paper written by Yu et al. indicated that the combined upregulation of two lncRNAs (PVT1 and uc002mbe.2) could provide a new method for the diagnosis of HCC, and the expression of PVT1 and uc002mbe. 2 was positively related to tumor size and clinical stage in HCC patients [33]. Furthermore, Gou et al. found that PVT1 could promote cell proliferation and invasion in HCC by regulating miR-214 expression [39]. Moreover, this is the first meta-analysis to survey the expression and the potential value of PVT1 in HCC. The 0.55 SMD $(0.38,0.71)$ of this meta-analysis verified that HCC cells had high expressions of PVT1. Furthermore, in the diagnostic meta-analysis, 840 cases from GEO, TCGA, and inhouse RT-qPCR were included, and the results were analyzed to estimate the validity for the detection of PVT1 in HCC. The sensitivity of the PVT1 assay in the included parts ranged from $41 \%$ to $76 \%$, and the specificity ranged from $71 \%$ to $96 \%$. The combined sensitivity (0.77) and specificity (0.84) values demonstrated the accuracy of using PVT1 expression to detect HCC. Also, our results had an AUC of 0.81 , which indicated that PVT1 could be of moderate value in discriminating HCC patients from normal controls [40]. A PLR value of 5.27 suggested that patients with HCC had an approximately 5.27-fold higher chance of being PVT1 assay-positive. However, there were some limitations in our meta-analysis. High heterogeneity could not be avoided partly because of blinding in the three included databases (GEO, TCGA, and in-house RT-qPCR), and we applied sensitivity analysis to exclude two data sources (GSE54236 and TCGA) to reduce heterogeneity. In addition, no adequate data from publications was found on the clinical value of PVT1 in HCC, which may be another limitation of our meta-analysis.

In addition, SMMC-7721 cells were transfected with siRNA-PVT1 to inhibit the expression of PVT1. Along with the knockdown of PVT1, the expression of 195 genes and 60 genes were respectively upregulated and downregulated. Then, we focused on the use of GEO, TCGA, a gene microarray and prediction algorithms, to identify miR-424-5p and INCENP as candidates for further analysis. We performed various experiments to confirm the role of PVT1, miR-424-5p, and INCENP in HCC. Taken the results together, we hypothesized that $P V T 1$ could affect the biological function of HCC cells by targeting miR-424-5p and regulating INCENP. Focusing on this new insight into the PVT1/miR-424-5p/INCENP axis, this study provided a novel target for the clinical prevention of and therapeutic strategy for HCC.

As previously reported, $m i R-424-5 p$ is related to the progression of different cancers [41-44]. For example, Zhang et al. found that miR-424 was related to the pathological stage and poor prognosis of gastric cancer patients [41]. Wei et al. found that miR-424-5p could promote the proliferation of gastric cancer via targeting SMAD3 by the TGF- $\beta$ signaling pathway [42]. Zhou et al. found that miR-424-5p could function as an anti-oncogene in the growth of cervical cancer cell by targeting KDM5B through the Notch signaling pathway [43]. Zhang et al. found that miR-424-5p was clearly downregulated in HCC tissues, and the low expression of $m i R-424-5 p$ was critically correlated with higher pathological grades and TNM stages. Also, aberrant $m i R-424-5 p$ expression is significantly involved in the progression of liver cancer [44]. Furthermore, growing evidence has confirmed the role of INCENP in cancers [45-47]. For example, Deng et al. confirmed that the methylation of INCENP could be involved in the growth of cancer cells [45]. Xia et al. demonstrated that the high expression of INCENP was associated with shorter survival in HCC patients [46]. Moreover, Adams et al. confirmed high INCENP levels in colon, testes, and prostate cancer cells [47]. In our current study, we verified the presence of the decreased expression of $m i R-424-5 p$ and the overexpression of INCENP in HCC. Also, complementary sequences and the correlation between PVT1, miR424-5p, and INCENP supported our hypothesis.

\section{KARGER}


In the pathway analysis, we found that overlapping genes were significantly overrepresented in the cell cycle and the p53 signaling pathway, supporting our results that PVT1 might play a vital role in the proliferation of HCC. The p53 signaling pathway is associated with the cell cycle, apoptosis, and poor prognosis for cancer patients [48-50]. These findings suggest that PVT1 affects the carcinogenesis and progression of HCC by modulating the expression of miR-424-5p and INCENP through the p53 signaling pathway.

Overall, our study indicated that PVT1 might serve as an oncogene to facilitate the progression of HCC by targeting miR-424-5p and regulating INCENP. However, the precise mechanism remains unknown, and further investigations are urgently needed.

\section{Acknowledgements}

This study was supported by the Guangxi Medical University Training Program for Distinguished Young Scholars (2017), Medical Excellence Award Funded by the Creative Research Development Grant from the First Affiliated Hospital of Guangxi Medical University and the Guangxi Science and Technology Program (Guike17195020).

\section{Disclosure Statement}

The authors declare that there are no conflict of interests.

\section{References}

1 Torre LA, Bray F, Siegel RL, Ferlay J, Lortet-Tieulent J, Jemal A: Global cancer statistics, 2012 CA Cancer J Clin 2015;65:87-108.

- Moriguchi M, Takayama T, Higaki T, Kimura Y, Yamazaki S, Nakayama H, Ohkubo T, Aramaki O: Early cancerrelated death after resection of hepatocellular carcinoma. Surgery 2012;151:232-237.

3 Guo Z, Zhong JH, Jiang JH, Zhang J, Xiang BD, Li LQ: Comparison of survival of patients with bclc stage a hepatocellular carcinoma after hepatic resection or transarterial chemoembolization: A propensity scorebased analysis. Ann Surg Oncol 2014;21:3069-3076.

4 Chiche L, Menahem B, Bazille C, Bouvier V, Plard L, Saguet V, Alves A, Salame E: Recurrence of hepatocellular carcinoma in noncirrhotic liver after hepatectomy. World J Surg 2013;37:2410-2418.

5 Batista PJ, Chang HY: Long noncoding rnas: Cellular address codes in development and disease. Cell 2013;152:1298-1307.

6 Mercer TR, Dinger ME, Mattick JS: Long non-coding rnas: Insights into functions. Nat Rev Genet 2009;10:155-159.

7 Zhu P, Wang Y, Wu J, Huang G, Liu B, Ye B, Du Y, Gao G, Tian Y, He L, Fan Z: Lncbrm initiates yap1 signalling activation to drive self-renewal of liver cancer stem cells. Nat Commun 2016;7:13608.

$>8$ Cao C, Sun J, Zhang D, Guo X, Xie L, Li X, Wu D, Liu L: The long intergenic noncoding rna ufc1, a target of microrna $34 \mathrm{a}$, interacts with the mrna stabilizing protein hur to increase levels of beta-catenin in hcc cells. Gastroenterology 2015;148:415-426 e418.

-9 Zhou M, Zhang XY, Yu X: Overexpression of the long non-coding rna spry4-it1 promotes tumor cell proliferation and invasion by activating ezh2 in hepatocellular carcinoma. Biomed Pharmacother 2017;85:348-354.

10 Li SP, Xu HX, Yu Y, He JD, Wang Z, Xu YJ, Wang CY, Zhang HM, Zhang RX, Zhang JJ, Yao Z, Shen ZY: Lncrna hulc enhances epithelial-mesenchymal transition to promote tumorigenesis and metastasis of hepatocellular carcinoma via the mir-200a-3p/zeb1 signaling pathway. Oncotarget 2016;7:42431-42446.

11 Jin W, Chen L, Cai X, Zhang Y, Zhang J, Ma D, Cai X, Fu T, Yu Z, Yu F, Chen G: Long non-coding rna tuc338 is functionally involved in sorafenib-sensitized hepatocarcinoma cells by targeting rasal1. Oncol Rep 2017;37:273-280.

12 Yin X, Zheng SS, Zhang L, Xie XY, Wang Y, Zhang BH, Wu W, Qiu S, Ren ZG: Identification of long noncoding rna expression profile in oxaliplatin-resistant hepatocellular carcinoma cells. Gene 2017;596:53-88.

13 Colombo T, Farina L, Macino G, Paci P: Pvt1: A rising star among oncogenic long noncoding rnas. Biomed Res Int 2015;2015:304208. 


\section{Cellular Physiology Cell Physiol Biochem 2018;47:2216-2232 \begin{tabular}{l|l} 
DOI: 10.1159/000491534 2018 & $\begin{array}{l}\text { O 2018 The Author(s). Published by S. Karger AG, Basel } \\
\text { www.karger.com/cpb }\end{array}$ \\
\hline
\end{tabular} \\ Zhang et al.: PVT1 in Hepatocellular Carcinoma}

14 Cui M, You L, Ren X, Zhao W, Liao Q, Zhao Y: Long non-coding rna pvt1 and cancer. Biochem Biophys Res Commun 2016;471:10-14.

15 Xu MD, Wang Y, Weng W, Wei P, Qi P, Zhang Q, Tan C, Ni SJ, Dong L, Yang Y, Lin W, Xu Q, Huang D, Huang Z, Ma Y, Zhang W, Sheng W, Du X: A positive feedback loop of Incrna-pvt1 and foxm1 facilitates gastric cancer growth and invasion. Clin Cancer Res 2017;23:2071-2080.

16 Liu HT, Fang L, Cheng YX, Sun Q: Lncrna pvt1 regulates prostate cancer cell growth by inducing the methylation of mir-146a. Cancer Med 2016;5:3512-3519.

-17 Liu E, Liu Z, Zhou Y: Carboplatin-docetaxel-induced activity against ovarian cancer is dependent on upregulated lncrna pvt1 Int J Clin Exp Pathol 2015;8:3803-3810.

18 Zhang XW, Bu P, Liu L, Zhang XZ, Li J: Overexpression of long non-coding rna pvt1 in gastric cancer cells promotes the development of multidrug resistance. Biochem Biophys Res Commun 2015;462:227-232.

19 Liu F, Dong Q, Huang J: Overexpression of lncrna pvt1 predicts advanced clinicopathological features and serves as an unfavorable risk factor for survival of patients with gastrointestinal cancers. Cell Physiol Biochem 2017;43:1077-1089.

20 Wu D, Li Y, Zhang H, Hu X: Knockdown of Incrna pvt1 enhances radiosensitivity in non-small cell lung cancer by sponging mir-195 Cell Physiol Biochem 2017;42:2453-2466.

21 Pang C, Liu M, Fang W, Guo J, Zhang Z, Wu P, Zhang Y, Wang J: Mir-139-5p is increased in the peripheral blood of patients with prostate cancer. Cell Physiol Biochem 2016;39:1111-1117.

22 Dai J, Wu H, Zhang Y, Gao K, Hu G, Guo Y, Lin C, Li X: Negative feedback between tap63 and mir-133b mediates colorectal cancer suppression. Oncotarget 2016;7:87147-87160.

-23 Wu H, Zhou J, Zeng C, Wu D, Mu Z, Chen B, Xie Y, Ye Y, Liu J: Curcumin increases exosomal tcf21 thus suppressing exosome-induced lung cancer. Oncotarget 2016;7:87081-87090.

-24 Dinh TA, Vitucci EC, Wauthier E, Graham RP, Pitman WA, Oikawa T, Chen M, Silva GO, Greene KG, Torbenson MS, Reid LM, Sethupathy P: Comprehensive analysis of the cancer genome atlas reveals a unique gene and non-coding rna signature of fibrolamellar carcinoma. Sci Rep 2017;7:44653.

25 Seiler R, Black PC, Thalmann G, Stenzl A, Todenhofer T: Is the cancer genome atlas (tcga) bladder cancer cohort representative of invasive bladder cancer? Urol Oncol 2017;35:458 e451-458 e457.

26 Gao H, Wang H, Yang W: Identification of key genes and construction of microrna-mrna regulatory networks in multiple myeloma by integrated multiple geo datasets using bioinformatics analysis. Int J Hematol 2017;106:99-107.

27 Mao Y, Xu X, Wang X, Zheng X, Xie L: Is angiotensin-converting enzyme inhibitors/angiotensin receptor blockers therapy protective against prostate cancer? Oncotarget 2016;7:6765-6773.

28 Khan A, Mathelier A: Intervene: A tool for intersection and visualization of multiple gene or genomic region sets. BMC Bioinformatics 2017;18:287.

29 Zhou Y, Liao Q Li X, Wang H, Wei F, Chen J, Yang J, Zeng Z, Guo X, Chen P, Zhang W, Tang K, Li X, Xiong W, Li G: Hyou1, regulated by lplunc1, is up-regulated in nasopharyngeal carcinoma and associated with poor prognosis. J Cancer 2016;7:367-376.

-30 Xiao X, Zhou X, Ming H, Zhang J, Huang G, Zhang Z, Li P: Chick chorioallantoic membrane assay: A 3d animal model for study of human nasopharyngeal carcinoma. PloS one DOI: 10.1371/journal.pone.0130935.

-31 Mirsafian H, Ripen AM, Leong WM, Chear CT, Bin Mohamad S, Merican AF: Transcriptome profiling of monocytes from xla patients revealed the innate immune function dysregulation due to the btk gene expression deficiency. Sci Rep 2017;7:6836.

32 Zhao Z, Bai J, Wu A, Wang Y, Zhang J, Wang Z, Li Y, Xu J, Li X: Co-lncrna: Investigating the Incrna combinatorial effects in go annotations and kegg pathways based on human rna-seq data. Database DOI: 10.1093/database/bav082.

33 Ponting CP, Oliver PL, Reik W: Evolution and functions of long noncoding rnas. Cell 2009;136:629-641.

-34 Tsai MC, Manor O, Wan Y, Mosammaparast N, Wang JK, Lan F, Shi Y, Segal E, Chang HY: Long noncoding rna as modular scaffold of histone modification complexes. Science 2010;329:689-693.

35 Yu J, Han J, Zhang J, Li G, Liu H, Cui X, Xu Y, Li T, Liu J, Wang C: The long noncoding rnas pvt1 and uc002mbe. 2 in sera provide a new supplementary method for hepatocellular carcinoma diagnosis. Medicine DOI: 10.1097/MD.0000000000004436.

-36 Zheng X, Hu H, Li S: High expression of Incrna pvt1 promotes invasion by inducing epithelial-tomesenchymal transition in esophageal cancer. Oncol Lett 2016;12:2357-2362. 


\section{Cellular Physiology Cell Physiol Biochem 2018;47:2216-2232 \begin{tabular}{l|l} 
DOI: 10.1159/000491534 2018 & $\begin{array}{l}\text { O 2018 The Author(s). Published by S. Karger AG, Basel } \\
\text { www.karger.com/cpb }\end{array}$ \\
\hline
\end{tabular}

37 You L, Chang D, Du HZ, Zhao YP: Genome-wide screen identifies pvt1 as a regulator of gemcitabine sensitivity in human pancreatic cancer cells. Biochem Biophys Res Commun 2011;407:1-6.

-38 Ding C, Yang Z, Lv Z, Du C, Xiao H, Peng C, Cheng S, Xie H, Zhou L, Wu J, Zheng S: Long non-coding rna pvt1 is associated with tumor progression and predicts recurrence in hepatocellular carcinoma patients. Oncol Lett 2015;9:955-963.

39 Gou X, Zhao X, Wang Z: Long noncoding rna pvt1 promotes hepatocellular carcinoma progression through regulating mir-214 Cancer Biomark 2017; 20:511-519.

40 Swets JA: Measuring the accuracy of diagnostic systems. Science 1988;240:1285-1293.

-41 Zhang J, Liu H, Hou L, Wang G, Zhang R, Huang Y, Chen X, Zhu J: Circular rna_larp4 inhibits cell proliferation and invasion of gastric cancer by sponging mir-424-5p and regulating lats1 expression. Mol Cancer 2017;16:151.

-42 Wei S, Li Q, Li Z, Wang L, Zhang L, Xu Z: Correction: Mir-424-5p promotes proliferation of gastric cancer by targeting smad3 through tgf-beta signaling pathway. Oncotarget 2017;8:34018.

43 Zhou Y, An Q Guo RX, Qiao YH, Li LX, Zhang XY, Zhao XL: Mir424-5p functions as an anti-oncogene in cervical cancer cell growth by targeting kdm5b via the notch signaling pathway. Life Sci 2017;171:9-15.

44 Zhang Y, Li T, Guo P, Kang J, Wei Q Jia X, Zhao W, Huai W, Qiu Y, Sun L, Han L: Mir-424-5p reversed epithelial-mesenchymal transition of anchorage-independent hcc cells by directly targeting icat and suppressed hcc progression. Sci Rep 2014;4:6248.

45 Deng X, Von Keudell G, Suzuki T, Dohmae N, Nakakido M, Piao L, Yoshioka Y, Nakamura Y, Hamamoto R: Prmt1 promotes mitosis of cancer cells through arginine methylation of incenp. Oncotarget 2015;6:3517335182.

46 Xia R, Chen S, Chen Y, Zhang W, Zhu R, Deng A: A chromosomal passenger complex protein signature model predicts poor prognosis for non-small-cell lung cancer. Onco Targets Ther 2015;8:721-726.

47 Adams RR, Eckley DM, Vagnarelli P, Wheatley SP, Gerloff DL, Mackay AM, Svingen PA, Kaufmann SH, Earnshaw WC: Human incenp colocalizes with the aurora-b/airk2 kinase on chromosomes and is overexpressed in tumour cells. Chromosoma 2001;110:65-74.

48 Fan M, Shen J, Liu H, Wen Z, Yang J, Yang P, Liu K, Chang Y, Duan J, Lu K: Downregulation of prrx1 via the p53-dependent signaling pathway predicts poor prognosis in hepatocellular carcinoma. Oncol Rep 2017;38:1083-1090.

49 Wang P, Cui J, Wen J, Guo Y, Zhang L and Chen X. Cisplatin induces HepG2 cell cycle arrest through targeting specific long noncoding RNAs and the p53 signaling pathway. Oncol Lett 2016; 12: 4605-4612.

-50 Sun Y, Tao C, Huang X, He H, Shi H, Zhang Q Wu H: Metformin induces apoptosis of human hepatocellular carcinoma hepg2 cells by activating an ampk/p53/mir-23a/foxa1 pathway. Onco Targets Ther 2016;9:2845-2853.

51 Villa E, Critelli R, Lei B, Marzocchi G, Camma C, Giannelli G, Pontisso P, Cabibbo G, Enea M, Colopi S, Caporali C, Pollicino T, Milosa F, Karampatou A, Todesca P, Bertolini E, Maccio L, Martinez-Chantar ML, Turola E, Del Buono M, De Maria N, Ballestri S, Schepis F, Loria P, Enrico Gerunda G, Losi L, Cillo U: Neoangiogenesisrelated genes are hallmarks of fast-growing hepatocellular carcinomas and worst survival. Results from a prospective study. Gut 2016;65:861-869.

52 Shi M, Chen MS, Sekar K, Tan CK, Ooi LL, Hui KM: A blood-based three-gene signature for the non-invasive detection of early human hepatocellular carcinoma. Eur J Cancer 2014;50:928-936.

53 Wang YH, Cheng TY, Chen TY, Chang KM, Chuang VP, Kao KJ: Plasmalemmal vesicle associated protein (plvap) as a therapeutic target for treatment of hepatocellular carcinoma. BMC cancer 2014;14:815.

54 Hui KM: Gene expression profiling of PBMC from normal individuals, chronic hepatitis B carriers and hepatocellular carcinoma patients. https://www.ncbi.nlm.nih.gov/geo/query/acc.cgi?acc= GSE58208.

55 Xie Z, Wu B: Salivary lnc-PCDH9-13:1 and miR-664a-5p are Novel Hypersensitive and Specific Biomarkers in Diagnosis of Early Hepatocellular Carcinoma. https://www.ncbi.nlm.nih.gov/geo/query/acc.cgi?acc= GSE98269

56 Wang K, Guo W. The gene expression profiling array of LncRNA between tumor tissues and paired nontumor tissues in HBV-positive hapatocellular carcinoma. https://www.ncbi.nlm.nih.gov/geo/query/acc. cgi?acc $=$ GSE49713.

-57 Mah WC, Thurnherr T, Chow PK, Chung AY, Ooi LL, Toh HC, Teh BT, Saunthararajah Y, Lee CG: Methylation profiles reveal distinct subgroup of hepatocellular carcinoma patients with poor prognosis. PloS one DOI: 10.1371/journal.pone.0104158. 